\title{
O manual do professor: orientações para o ensino e a avaliação da leitura em livros didáticos do ensino fundamental II
}

\author{
El manual del profesor: orientaciones para la enseñanza y \\ la evaluación de la lectura en libros didácticos de la \\ enseñanza fundamental II
}

\author{
Márcia Andréa Almeida de Oliveira ${ }^{1}$ \\ Lívia Cristina Virgolino da Silva²
}

\begin{abstract}
RESUMO: Neste artigo, apoiando-nos na abordagem qualitativa de pesquisa, verificamos de que forma as orientações sobre o ensino presentes no Manual do Professor podem viabilizar a avaliação formativa da leitura. Para isso, inicialmente, realizamos uma pesquisa bibliográfica sobre o tema, seguida da seleção de dois Manuais do Professor, de livros didáticos do $8^{\circ}$ ano, utilizados em escolas públicas de Belém e aprovados no PNLD/2014. Depois, descrevemos os Manuais, observando as discussões teóricas e orientações metodológicas destinadas à leitura e à avaliação e, em seguida, analisamo-los, valendonos dos estudos desenvolvidos por Batista (2009) sobre livro didático, por Solé (1998) e Koch e Elias (2014) sobre leitura, por Allal (1986) e Hadji (2011) sobre avaliação formativa e por Condemarín e Medina (2005) e Beserra (2007) sobre avaliação da leitura. Após a reflexão dos Manuais, orientada pelas perguntas de pesquisa, observamos que esses trazem reflexões para o ensino de leitura, sob o viés do cognitivismo e do interacionismo. Em relação à avaliação, verificamos que se assume a concepção formativa de avaliação; no entanto, não são propostos instrumentos e critérios para o professor avaliar a leitura. Com base nos dados, argumentamos que as orientações sobre o ensino e a avaliação da leitura não são suficientes para o professor realizar um trabalho que favoreça 0 desenvolvimento das habilidades de leitura dos alunos.
\end{abstract}

PALAVRAS-CHAVE: Livro Didático. Manual do professor. Leitura. Avaliação formativa.

RESUMEN: En este artículo, apoyándonos en el abordaje cualitativo de investigación, verificamos de qué forma las orientaciones sobre la enseñanza presentes en el Manual del Profesor pueden viabilizar la evaluación formativa de la lectura. Para ello, inicialmente, realizamos una investigación bibliográfica sobre el tema, seguida de la selección de dos

1 Doutorado em Linguística Aplicada pela Universidade de Campinas, com estágio doutoral na Universidade de Genebra. Mestrado em Letras: Linguística e Teoria Literária pela Universidade Federal do Pará. Professora adjunta da Universidade Federal do Pará. Tem experiência na área de Linguística e Linguística Aplicada, atuando principalmente nos seguintes temas: didatização de gêneros textuais, gestos didáticos/profissionais, avaliação da aprendizagem e livro didático. E-mail: dryoliv@hotmail.com.

2 Graduada em Letras (Licenciatura em Língua Portuguesa) pela Universidade Federal do Pará. E-mail: liviavirgolino@hotmail.com. 
Manuales del Profesor, de libros didácticos del $8^{\circ}$ año, utilizados en escuelas públicas de Belém y aprobados en el PNLD/2014. A continuación, describimos los manuales, observando las discusiones teóricas y orientaciones metodológicas para la lectura y la evaluación y, a continuación, los analizamos, valiéndonos de los estudios desarrollados por Batista (2009) sobre libro didáctico, por Solé (1998) y Koch y Elias (2014) sobre lectura, por Allal (1986) y Hadji (2011) sobre evaluación formativa y por Condemarín y Medina (2005) y Beserra (2007) sobre evaluación de la lectura. Después de la reflexión de los manuales, orientada por las preguntas de investigación, observamos que estos traen reflexiones para la enseñanza de lectura, bajo el sesgo del cognitivismo y del interaccionismo. En relación a la evaluación, verificamos que se asume la concepción formativa de evaluación; sin embargo, no se proponen instrumentos y criterios para el profesor evaluar la lectura. En base a los datos, argumentamos que las orientaciones sobre la enseñanza y la evaluación de la lectura no son suficientes para que el profesor realice un trabajo que favorezca el desarrollo de las habilidades de lectura de los alumnos.

PALABRAS CLAVE: Libro Didáctico. Manual del profesor. Lectura. Evaluación formativa.

\section{Introdução}

Esta pesquisa busca saber de que forma o Manual do Professor (MP) de dois livros didáticos (LD) do $8^{\circ}$ ano de duas coleções - Singular e Plural (2012) e Vontade de Saber: Português (2012) -, utilizadas em escolas do município de Belém e aprovadas no Programa Nacional de Livro Didático (PNLD) de 2014, contribuem para o ensino e a avaliação da compreensão leitora.

A fim de orientar a coleta e a análise dos MP, adotamos, quanto à abordagem, a pesquisa qualitativa; quanto aos objetivos, as pesquisas descritiva e exploratória; e quanto ao procedimento, as pesquisas bibliográfica e documental.

Quanto ao referencial teórico adotado, baseamo-nos nos estudos sobre LD (considerando-o um gênero discursivo), sobre leitura (assumindo a concepção interativa de leitura) e sobre avaliação (reconhecendo o papel fundamental da avaliação formativa no ensino e na aprendizagem da leitura).

Neste artigo, primeiramente, discutimos sobre o LD e a relação que o professor mantém com esse material didático, conforme Batista (2009). Após isso, discorremos sobre os estudos a respeito da leitura, dando ênfase aos princípios da concepção sociocognitiva e interativa, de acordo com Solé (1998) e 
Koch e Elias (2014). Depois, dissertamos acerca da concepção de avaliação formativa, segundo Hadji (2011), e avaliação da leitura, consoante Condemarín e Medina (2005). Em seguida, apresentamos os procedimentos metodológicos adotados no trabalho, especificando os tipos e técnicas de pesquisas utilizados. Por fim, analisamos como o MP colabora para a implementação de práticas de ensino e de avaliação da compreensão da leitura em Língua Portuguesa, de modo a fomentar a aprendizagem dos alunos.

\section{O livro didático: definição e relação com o professor}

Batista (2009, p. 41) conceitua o LD como "aquele livro [...] empregado pela escola, para o desenvolvimento de um processo de ensino ou de formação" (grifos do autor). De acordo com o autor, a conceituação do LD pode apresentar problemas devido a um conjunto de aspectos que esse apresenta, como a heterogeneidade dos suportes, a variação dos meios de reprodução, a variação nos modos de produção, a diversidade nos modos de sua utilização, entre outros. Soares (2007, p. 17) acrescenta que o LD é um produto que visa a "satisfazer expectativas de venda, de veiculação de valores" e também é um "instrumento de formação de condutas pedagógicas na medida em que orienta práticas de leitura e interpretação de texto e correção de exercícios, por exemplo".

De acordo com a literatura sobre o tema, existem duas abordagens acerca do LD: uma o considera como suporte de textos em gêneros variados e didatizados e outra que o toma como enunciado em um gênero discursivo. Marcuschi (2008) concebe o LD como um suporte convencional de textos diversos, de gêneros variados, que, ao serem incorporados ao LD de Língua Portuguesa, não mudam suas características, embora isso mude sua funcionalidade, fato denominado por ele como reversibilidade de função. Bunzen e Rojo (2005), por sua vez, afirmam que esse livro é um gênero discursivo e não um suporte, pois nele há unidade discursiva, autoria e estilo, que compreendem as conciliações dos discursos autorais, a articulação de gêneros diversos. 
Considerando essas diferenças, reconhecemos assim como Bunzen e Rojo (2005) que o LD é muito mais do que um conjunto de textos inseridos em um suporte, sem um alinhamento, estilo e autoria.

\begin{abstract}
Quando os autores e editores de LDP selecionam/negociam determinados objetos de ensino e elaboram um livro didático, com capítulos e/ou unidades didáticas, para ensiná-los, eles estão, no nosso entender, produzindo um enunciado em um gênero do discurso, cuja função social é re(a)presentar, para cada geração de professores e estudantes, o que é oficialmente reconhecido ou autorizado como forma de conhecimento sobre a língua(gem) e sobre as formas de ensino-aprendizagem. (BUNZEN; ROJO, 2005, p.87)
\end{abstract}

Portanto, enquanto um enunciado no gênero do discurso, os LD são oriundos das interações que os autores mantêm com enunciados anteriores e ulteriores. O LD é iluminado pelos discursos de outrem, é perpassado por apreciações e entonações.

Pois todo discurso concreto (enunciação) encontra aquele objeto para
o qual está voltado sempre, por assim dizer, já desacreditado,
contestado, avaliado, envolvido por sua névoa escura ou, pelo
contrário, iluminado pelos discursos de outrem que já falaram sobre
ele. O objeto está amarrado e penetrado por ideias gerais, por pontos
de vista, por apreciações de outros e por entonações. Orientado para o
seu objeto, o discurso penetra neste meio dialogicamente perturbado
e tenso de discursos de outrem, de julgamentos e de entonações. Ele
se entrelaça com eles em interações complexas, fundindo-se com uns,
isolando-se de outros, cruzando com terceiros; e tudo isso pode formar
substancialmente o discurso, penetrar em todos os seus estratos
semânticos, tornar complexa a sua expressão, influenciar todo o seu
aspecto estilístico. (BAKHTIN, 1993, p. 86).

Ao entrar então em contato com o $L D$, o professor não está mantendo contato apenas com textos, está tendo acesso a discursos sobre o que é e como ensinar, uma vez que o planejamento das seções, a seleção de gêneros, textos e temas, bem como a construção das atividades refletem concepções de ensino e de aprendizagem e maneiras de ver o professor e conceber a elaboração didática. Isso é verificável na própria evolução do livro. Como Soares (2001) destaca, ao longo dos anos, o LD sofreu transformação em função das mudanças 
no professorado (e no alunado), o que fez com que de uma coletânea de textos passasse a ser uma coletânea de textos e atividades e, depois, a uma coletânea de textos, atividades e respostas dos exercícios. A autora afirma, entre outras coisas, que nas primeiras décadas do século $\mathrm{XX}$, por meio do material, é possível perceber

uma concepção de professor a quem bastava que o manual didático oferecesse os textos, numa antologia austera, um professor que, considerado bom leitor e conhecedor de língua e literatura, seria capaz de, autonomamente, definir uma metodologia de trabalho com textos, na sala de aula; progressivamente, e sobretudo a partir dos anos 70, uma concepção de professor a quem o livro didático deve oferecer não só os textos, mas também a orientação metodológica para a sua leitura e interpretação, as atividades didáticas a serem realizadas e até mesmo as respostas às questões de compreensão e interpretação dos textos, um professor talvez não considerado propriamente um mau leitor, ou incapaz de definir por si mesmo uma metodologia de estudo de textos na sala de aula, mas reconhecido como sem formação e sem tempo suficientes para a preparação de suas aulas. (SOARES, 2001, p. 73).

De acordo com Britto (2002), o modelo atual de LD está atrelado a um processo de massificação do ensino e à depreciação da função docente. Soares (2002) também menciona que as novas condições de trabalho, instauradas principalmente a partir da década de 1970 , levaram os professores a buscar formas de facilitação de sua atividade docente.

Com base na literatura sobre o assunto, percebemos que, com o passar dos anos, o livro foi ganhando um papel de destaque nas políticas públicas e passou a ser considerado um material formativo também, como é declarado no Guia de Livros Didáticos: O MP deve "fornecer subsídios para a atualização e a formação do professor, tais como bibliografias básicas, sugestões de leitura suplementar, sugestões de integração com outras disciplinas ou de exploração de temas transversais, dentre outros." (BRASIL, 2013a, p. 20, grifos do autor).

Contudo, qualquer política de LD só será eficiente, se houver a reorganização do sistema educacional e o investimento na formação dos professores em instituições de ensino, pois

[...] é preciso reforçar a tese de que a formação do professor é tarefa da instituição de ensino [...] nos cursos universitários. Deve ser, pois, 
com base nas orientações recebidas nessas instituições que o professor poderá saber o que fazer com o livro ou com os livros didáticos em suas aulas. O professor deveria saber o porquê dos conteúdos selecionados e as implicações das estratégias utilizadas nos livros didáticos. (DIONÍSIO; BEZERRA, 2001, p.85).

Fundamentando-nos em tais discussões, pensamos que o LD é um importante instrumento que pode auxiliar o trabalho do professor em sala de aula, pela possibilidade que oferece: 0 aluno pode ter acesso a diversos textos de diferentes gêneros e que circularam em múltiplos suportes, a atividades que englobam diferentes práticas de linguagem (escrita, leitura, oralidade) e de análise linguística etc. Contudo, isso não isenta o professor de dominar os saberes da formação profissional, disciplinares e curriculares (TARDIF, 2008), porque sem eles não é possível selecionar e organizar os conteúdos mais significativos em função das dificuldades e potencialidades de aprendizagem; escolher procedimentos e recursos, para desencadear um ensino mais eficiente, orientando o docente no como e com que deve agir; integrar as etapas do ensino, dando continuidade a este.

Consideramos, assim, que o LD é um instrumento que pode participar positivamente do processo de ensino, desde que haja uma articulação com o contexto escolar, a apropriação dos princípios teórico-metodológicos que orientam a sua produção e, por conseguinte, a adaptação das propostas às necessidades de aprendizagem.

\section{Leitura: um processo sociocognitivo e interativo}

Segundo Solé (1998, p.23), a leitura é um "objeto de conhecimento em si mesmo" e "instrumento necessário para a realização de novas aprendizagens". De acordo com a autora, a leitura é um processo de interação entre leitor e texto, em que o leitor busca alcançar seus objetivos e constrói um significado individual sobre os textos que lê, levando em consideração seus conhecimentos prévios e seus objetivos de leitura. A leitura é um processo, a partir do qual se compreende a escrita. 
Nesta compreensão intervêm tanto o texto, sua forma e conteúdo, como o leitor, suas expectativas e conhecimentos prévios. Para ler, necessitamos, simultaneamente, manejar com destreza as habilidades de decodificação e aportar ao texto nossos objetivos, ideias e experiências prévias; precisamos nos envolver em um processo de revisão e inferência contínua, que se apoia na informação proporcionada pelo texto e na nossa própria bagagem, e em um processo que permita encontrar evidência ou rejeitar as previsões e inferências antes mencionadas. (SOLÉ, 1998, p. 23).

$\mathrm{Na}$ atividade de leitura, também acionamos todo um sistema de valores, crenças e atitudes que dizem respeito ao modo como fomos sociabilizados. Nessa direção, Koch e Elias (2014) afirmam que a leitura é uma atividade interativa complexa de produção de sentidos, que envolve os conhecimentos linguísticos (ortográficos, gramaticais e lexicais), conhecimentos do mundo, conhecimentos de textos e conhecimentos de gêneros. O texto não é um simples produto de codificação, que será decodificado por um sujeito passivo. Trata-se, na acepção das autoras, de um processo do qual participam autor, leitor e texto, em que o leitor constrói sentidos, utilizando-se de estratégias de leitura, como antecipação e inferência.

A abordagem sociocognitivista e interativa de leitura relaciona-se à concepção de linguagem como interação. Nesse sentido, a leitura é um processo de produção de sentidos, não estando o sentido nem no texto nem no leitor e sim em uma relação dialógica. Segundo essa abordagem,

[...] os sujeitos são vistos como atores/construtores sociais, sujeitos ativos que - dialogicamente - se constroem e são construídos no texto, considerado o próprio lugar a interação e da constituição dos interlocutores". Nessa perspectiva, a leitura é uma atividade interativa altamente complexa de produção de sentidos, que se realiza evidentemente com base nos elementos linguísticos presentes na superfície textual e na sua forma de organização, mas requer a mobilização de um vasto conjunto de saberes no interior do evento comunicativo. (KOCH; ELIAS, 2014, p. 10-11, grifos dos autores)

Considerando assim as discussões feita por Solé (1998) e Koch e Elias (2014), entendemos a leitura como uma atividade que envolve a interação entre 
leitor, texto e autor, sendo todos influenciados pelo contexto social. $O$ ato de ler não consiste apenas em um momento de decodificação, mas também envolve construção e ressignificação de sentidos, que é possível por meio da mobilização de diferentes estratégias de leitura.

Sobre as estratégias, Koch e Elias (2014) demonstram que recorremos a várias estratégias de leitura no trabalho de construção de sentido, como seleção, antecipação, inferência e verificação. Segundo elas, na atividade de leitura,

\begin{abstract}
estabelecemos relações entre nossos conhecimentos anteriormente construídos e as novas informações contidas no texto, fazemos inferência, comparações, formulamos perguntas relacionadas com o seu conteúdo [...], processamos, criticamos, contrastamos e avaliamos as informações que nos são apresentadas, produzindo sentido para 0 que lemos. Em outras palavras, agimos estrategicamente, o que nos permite dirigir e autorregular nosso próprio processo de leitura. $(\mathrm{KOCH}$; ELIAS, 2014, p. 18)
\end{abstract}

Quanto a isso, Condemarín e Medina (2005) afirmam que na leitura o indivíduo pode se valer de três tipos de procedimentos que vão ajudá-lo a compreender melhor o que está lendo: (i) ativação e desenvolvimento de conhecimentos prévios; (ii) desenvolvimento e avaliação da construção do significado durante a leitura, estimulando inferências e previsões nesse momento; e (iii) desenvolvimento e avaliação da construção do significado dos textos, por meio de técnicas, como a recordação ou a paráfrase, o resumo e a leitura crítica.

Ainda no que diz respeito aos procedimentos de leitura, Solé (1998) menciona que, no ato de ler, estão envolvidas estratégias de leitura, que embora não configurem uma "receita" para realizar uma determinada ação, quando ensinadas, podem subsidiar o leitor a alcançar seus objetivos de leitura. Ela destaca que as estratégias são poderosas devido a um componente característico, que é o de envolver "autodireção [...] e autocontrole, isto é, a supervisão e avaliação do próprio comportamento em função dos objetivos que o guiam e da possibilidade de modificá-lo em caso de necessidade" (SOLÉ,1998, p. 69). 
Segundo a autora, as estratégias podem ser ensinadas, mas não com intuito de se prescrever o caminho de uma ação e, sim, de apresentar procedimentos que podem auxiliar o leitor no momento da leitura. Mas quais estratégias ensinar e por que ensiná-las? Ela apresenta uma gama de estratégias que podem ser ensinadas e acionadas antes da leitura, durante a leitura e depois da leitura, como: compreender os propósitos implícitos e explícitos da leitura; ativar e aportar à leitura conhecimentos prévios relevantes para o conteúdo em questão; dirigir a atenção ao fundamental; comprovar continuamente se a compreensão ocorre mediante a revisão e a recapitulação periódica e a autointerrogação; elaborar e provar inferências de vários tipos, como interpretações, hipóteses e previsões e conclusões, entre outras.

Ao defender o ponto de vista de que é possível ensinar as estratégias de leitura, a autora chama a atenção para o que é ensinar e o que é avaliar leitura. Ela afirma, por exemplo, que

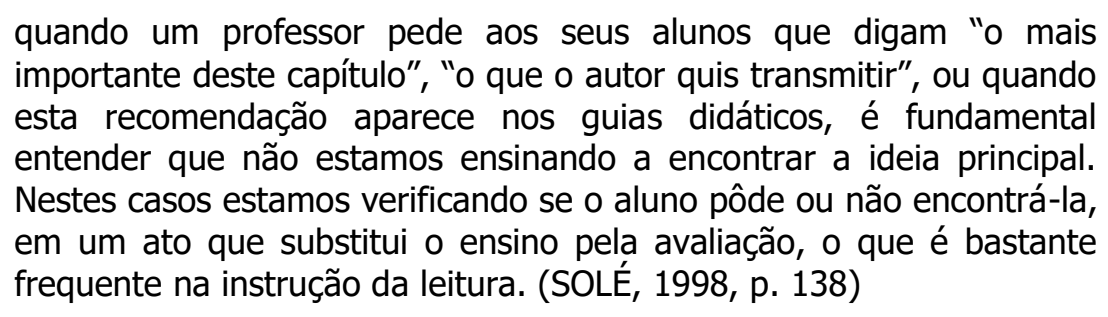

Esse trecho nos permite verificar claramente a diferença que a autora estabelece entre ensino de estratégias de leitura e avaliação da compreensão leitora, visto que esta última deve acontecer por meio da verificação da aprendizagem do aluno (a que perguntas de compreensão e interpretação ele consegue responder); já a primeira mostra-Ihe os percursos a seguir nas etapas (antes, durante e depois) de leitura.

Com base na concepção sociocognitivista e interativa de leitura e, especificamente, nas discussões de Solé (1998) sobre o ensino de estratégias, pretendemos analisar os MP das coleções didáticas selecionadas, verificando que 
orientações eles trazem que podem auxiliar o professor a encaminhar o ensino da leitura e, especificamente, a avaliar a compreensão leitora dos alunos.

\section{Avaliação formativa da leitura}

Hoje há um consenso no entendimento de que ensinar não é transmitir conhecimento e aprender não é simplesmente assimilar ideias. De acordo com Suassuna (2007, p. 37), as situações de ensino devem "instituir o pensamento crítico, favorecer a autonomia intelectual e a criatividade".

Nessa direção, Hoffman (2009, p.59) menciona que, para se pensar a avaliação,

há de se considerar as relações concretas que se travam entre os elementos da ação educativa, em nome da avaliação, e buscar uma consciência coletiva do significado desse processo. Para analisarmos a perspectiva da avaliação como uma ação mediadora, de fato, é preciso partir da negação da prática atual quanto ao seu caráter de terminalidade, de obstrução, de constatação de erros e acertos.

Considerando que, para mudar a realidade do ensino, é necessário, dentre outras coisas, mudar a maneira como se concebe avaliação, defendemos a avaliação formativa, tomando como pressuposto que "a avaliação de percursos de aprendizagem dos alunos no contexto das salas de aula só tem significado se estiver fortemente articulada com a aprendizagem e com o ensino" (FERNANDES, 2011, p. 2).

Sobre a avaliação formativa, Hadji (2011) afirma que ela consiste na realização de observação em sala de aula, de análise das dificuldades e potencialidades dos alunos, para ajudá-los a superar os problemas e ter êxito no processo de aprendizagem. Para o autor, o que caracteriza a avaliação formativa é, de modo geral, a vontade de colocarmos o nosso trabalho de observação realizado durante a aprendizagem a serviço do aluno, para ajudá-lo a ter êxito. Perrenoud (1998 apud HADJI, 2011), podemos dizer que "é formativa toda a avaliação que ajuda o aluno a aprender e a se desenvolver, ou seja, que participa 
da regulação das aprendizagens e do desenvolvimento no sentido de um projeto educativo".

A função reguladora da avaliação pode assumir formas diferentes: pode ser prognóstica, se controlar o acesso a um período escolar, somativa, se ocorrer no fim de um período de estudos, ou formativa, se fornecer "informações que permitam uma adaptação do ensino às diferenças individuais observadas na aprendizagem" (ALLAL, 1986, p. 177). Lançar mão dessas formas de avaliação permite compreender o que não funcionou e o que ainda falta para que os alunos atinjam o êxito.

Percebemos, assim, que a avaliação é um instrumento que tem por finalidade favorecer a aprendizagem dos alunos e não apenas quantificar e classificar.

No que diz respeito especificamente à avaliação da leitura, Colomer e Camps (2002, p. 173) destacam que

\begin{abstract}
as avaliações mais frequentes sobre leitura na escola se centram nas provas de velocidade leitora e nos questionários fechados de perguntas de compreensão sobre um texto. As provas de velocidade são provavelmente $o$ instrumento que se percebe com mais clareza como estritamente avaliador por parte dos professores. Algumas delas, baseadas na velocidade de leitura em voz alta, ofereceram a vantagem de obter com facilidade dados claros e objetivos que respondiam, além disso, ao aspecto leitor que a escola sempre entendeu como índice importante de progresso na leitura a partir da aprendizagem do código.
\end{abstract}

Parece não haver de fato uma preocupação na escola com a avaliação da leitura, enquanto compreensão. A prática avaliativa implementada não se preocupa com a formação de leitores competentes, pois se reduz, muitas vezes, à decodificação e à oralização. Considerando a visão formativa de avaliação, 0 ato de avaliar deveria informar o aluno e o professor sobre o nível de desenvolvimento e levar a regulação da aprendizagem, por meio da proposição de atividades ou de interações que permitissem ao aluno superar suas dificuldades. 
Tomando a abordagem formativa como pressuposto, a avaliação da leitura deve ser encaminhada a partir da observação sobre o que o aluno já sabe e das habilidades ainda não dominadas. Podemos dizer que a avaliação está intimamente ligada à prática de ensino de leitura e, por isso, cabe ao professor facilitar, apoiar e orientar a atividade do aluno, bem como "[...] criar as condições que facilitarão a atividade específica da aprendizagem dos alunos" (HADJI, 2011, p. 5).

De acordo com Perrenoud (1998 apud HADJI, 2011), o papel do docente é buscar perceber e compreender quais tipos de atividades favorecerão a aprendizagem dos alunos e priorizar a regulação das aprendizagens e não das tarefas; caso contrário, criará obstáculos para uma regulação formativa efetiva. Ele precisa propor ações e regulações apropriadas de acordo com o modo de aprender, o ritmo e as atitudes de cada aluno. É em função do desenvolvimento das habilidades de leitura que o professor deve agir em sala de aula.

A avaliação formativa da leitura requer mudanças no ensino e também a criação de novos instrumentos de avaliação, não apenas listas de perguntas de interpretação. Portanto, para a aprendizagem da leitura ocorrer, é necessário haver modificações nas estratégias didáticas implementadas, nas práticas de avaliação, na análise dos resultados dos alunos e na participação destes no processo de avaliação. É preciso que haja a integração do ensino, da avaliação e da aprendizagem.

Trazendo as discussões de Allal (1986, p. 178) para a reflexão sobre a avaliação formativa da leitura, elencamos algumas etapas para o professor conduzir o trabalho com essa prática, a saber:

1. Recolha de informações relativas aos progressos e às dificuldades de aprendizagem sentidos pelos alunos;

2. Interpretação das informações numa perspectiva de referência criterial e, na medida do possível, diagnóstico dos fatores que estão na origem das dificuldades de aprendizagem observadas no aluno;

3. Adaptação das atividades de ensino e de aprendizagem de acordo com a interpretação das informações recolhidas. 
Condemarín e Medina (2005) apresentam procedimentos que podem favorecer a realização das etapas elencadas acima, que permitem realizar a avaliação da leitura de forma integrada às atividades e que sejam mobilizados antes, durante e depois da leitura, como: perguntas prévias e formulação de hipóteses; técnica $\mathrm{C}-\mathrm{Q}-\mathrm{A}^{3}$; inferências e previsões e perguntas e respostas sobre o que se leu; recordações ou paráfrases; resumos etc. Essas estratégias vão permitir ao professor, por exemplo, verificar se o entendimento do aluno revela um nível de compreensão mais literal ou inferencial e implementar um trabalho sistemático com a leitura.

Considerando tal discussão, buscamos encontrar instruções no MP que subsidiem o trabalho de avaliação formativa da leitura. Nossa hipótese é de que essas orientações poderiam ampliar a concepção dos professores sobre o ensino de leitura e os tornar conscientes da importância do ensino de estratégias, tal como proposto por Solé (1998) e especificado por Condemarín e Medina (2005); estratégias essas que, uma vez dominadas pelos alunos, poderiam torná-los mais proficientes em leitura.

\section{Metodologia de pesquisa}

Neste trabalho, baseamo-nos na abordagem qualitativa de pesquisa, porque nos preocupamos "[...] com aspectos da realidade que não podem ser quantificados, [e centrando-nos] na compreensão e explicação da dinâmica das relações sociais" (GERHARDT; SILVEIRA, 2009, p. 32). Não buscamos provar ou quantificar dados, mas apenas descrever e explicar o nosso objeto de estudo, isto é, as orientações sobre avaliação, especificamente da leitura, presentes em dois MP.

Fundamentamo-nos também nas pesquisas bibliográfica e documental (GERHARDT; SILVEIRA, 2009), pois, além de fazermos um levantamento de

\footnotetext{
${ }^{3}$ Essa técnica "permite avaliar o conhecimento prévio dos alunos e seus propósitos em face de um texto expositivo", no momento em que o aluno é confrontado com os seguintes tipos de perguntas: "O que conheço sobre este tema?"; "O que quero aprender?" e "O que aprendi?". (CONDEMARÍN; MEDINA, 2005, p. 51)
} 
referências teóricas, como livros e artigos científicos para conhecer as discussões existentes sobre o tema, consultamos materiais já elaborados, como Guia de livros didáticos e dois MP de livros didáticos.

Para a revisão da literatura e a coleta de dados, inicialmente fizemos uma pesquisa bibliográfica acerca do PNLD, do LD, dos conceitos e concepções de leitura e da avaliação formativa. Depois, selecionamos dois LD do professor do $8^{\circ}$ ano que tinham sido aprovados no PNLD e que estavam sendo usados nas escolas públicas de Belém (Pará) em 2016. Os livros selecionados foram: Singular e Plural, de Figueiredo, Balthasar e Goulart e Vontade de saber, de Tavares e Conselvan.

Quanto ao tratamento dos dados, inicialmente, fizemos uma leitura dos MP das coleções escolhidas e, em seguida, passamos para sua descrição. Na leitura e descrição, destacamos somente as seções dos Manuais dedicadas ao ensino da leitura, ao ensino da leitura literária, às estratégias de leitura, à avaliação, às sugestões dadas ao professor para o uso da coleção e às respostas e aos comentários sobre como conduzir as atividades de compreensão textual. Após a descrição dos dados, buscamos organizá-los conforme as seguintes categorias: pressupostos teóricos sobre leitura; pressupostos teóricos sobre avaliação; e propostas de atividades e orientações para o ensino e a avaliação da leitura.

Com vistas a realizar a análise do corpus, levamos em consideração a leitura como uma atividade sociocognitivista e interativa e a abordagem formativa de avaliação, bem como as influências que o PNLD exerce sobre a produção do LD. E partimos da hipótese que as orientações presentes no MP sobre o ensino da leitura podem colaborar para a execução de práticas avaliativas que promovam o desenvolvimento de habilidades de leitura em Língua Portuguesa.

Durante a análise dos dados, tentamos identificar os pressupostos teóricometodológicos sobre leitura nos MP; verificar os pressupostos teóricometodológicos a respeito da avaliação nos MP; observar as orientações que os MP trazem sobre avaliação da leitura; e averiguar se as propostas de ensino 
possibilitam realizar a avaliação formativa da leitura. Tais objetivos foram elaborados em função do nosso problema de pesquisa: De que forma as orientações sobre o ensino presentes no MP podem viabilizar a avaliação formativa da leitura? e serviram para definirmos o tipo e a natureza da pesquisa e os textos e os documentos a serem estudados.

\section{Corpus de pesquisa: descrição dos dados}

O corpus da pesquisa é constituído de dois livros do $8^{\circ}$ ano do Ensino Fundamental II de duas coleções: Singular e Plural e Vontade de Saber. Tais coleções estão organizadas em livro do aluno e MP. Aqui vamos descrever apenas o Manual de cada livro.

\section{O Manual do Professor: Singular e Plural (MP1)}

O MP do volume do $8^{\circ}$ ano está organizado em: parte introdutória (apresentação, sumário); seguida de uma seção para explicar os pressupostos teórico-metodológicos, em que se discorre sobre o ensino de língua materna, leitura e produção de textos orais e escritos, leitura literária, conhecimentos linguísticos e avaliação da aprendizagem. Há também uma seção que traz orientações sobre como a coleção organiza o trabalho com avaliação. Nele, encontram-se também o mapa de conteúdos da coleção; sugestões de respostas, comentários e orientações para a mediação do professor; indicação de leituras complementares; e ficha de avaliação das produções textuais.

Nesse Manual, afirma-se que cada unidade do Caderno de Leitura $e$ Produção objetiva desenvolver as capacidades leitoras e produtoras em diferentes gêneros e que o Caderno de Práticas de Literatura visa a ajudar os alunos a tomar o objeto literário como situação interativa diferenciada, com base em exercícios que conjugam o contato com o texto.

Sobre o trabalho com leitura, menciona-se que as atividades de leitura devem levar os alunos a: interagir com a configuração textual; perceber os aspectos formais do texto; reconhecer as articulações desses aspectos com as situações de produção e os contextos de recepção; entre outros. 
O Manual do Professor: Vontade de saber (MP2)

O MP do volume do $8^{\circ}$ ano está organizado em: apresentação; sumário; orientações gerais, em que se apresentam cada seção e subseção da coleção e o mapa de conteúdos, e orientações didáticas e metodológicas, em que se discorre sobre o ensino de Língua Portuguesa no Brasil, os objetivos do ensino de Língua Portuguesa, a leitura em sala de aula, a diversidade de gêneros textuais, a interação entre textos, a produção escrita, a produção de gêneros orais, os conhecimentos linguísticos e a avaliação no ensino de Língua Portuguesa. Além disso, há a seção "objetivos, comentários e sugestões", em que são apresentadas orientações específicas para o desenvolvimento do trabalho proposto em cada uma das unidades e sugestões sobre como trabalhar os conteúdos selecionados.

De acordo com as orientações didáticas e metodológicas desse Manual, o objetivo do ensino de Língua Portuguesa, no que diz respeito aos procedimentos de leitura e de produção de textos, orais e escritos, é "promover o domínio dos quatro eixos básicos de nosso idioma - ouvir, falar, ler e escrever", sendo para isso necessário "a capacitação para uma comunicação eficiente envolvendo a leitura compreensiva e crítica, assim como a análise e compreensão da estrutura e funcionamento da língua" (TAVARES; CONSELVAN, 2012, p.15).

Nesse Manual, na seção destinada às orientações sobre a leitura em sala de aula, faz-se uma breve síntese do que é leitura, com base nos estudos de Solé (1998), e destaca-se que a leitura em sala de aula deve "[...] promover o ato de ler enquanto uma ação que desperte interesse e prazer [...]" nos alunos (TAVARES; CONSELVAN, 2012, p.19).

Nele, afirma-se ser necessário motivar os alunos diante das atividades de leitura e chama-se a atenção para o trabalho com os conhecimentos prévios. Para o trabalho com leitura, sugerem-se ainda algumas ideias, como exploração do título, da estrutura composicional, da autoria, entre outros aspectos. 
A respeito dos comentários e das sugestões das atividades de leitura encontrados nas orientações, elencam-se os seguintes objetivos: preparar a discussão sobre os assuntos tratados; motivar discussões sobre o tema; conhecer a opinião do aluno; compreender as principais características de um gênero; identificar os narradores de um texto; explorar o conhecimento do aluno acerca de escritores e de obras da literatura brasileira e universal etc.

\section{Interpretação dos dados: o Manual do Professor de dois livros didáticos de Língua Portuguesa}

A análise de dados foi organizada em função dos objetivos de pesquisa com a intenção de verificar as contribuições que as coleções Singular e Plural e Vontade de Saber oferecem para o ensino da leitura e sua avaliação. Nas subseções seguintes, pretendemos responder a estas perguntas: Quais são os pressupostos teórico-metodológicos sobre a leitura nos MP?; Quais são os pressupostos teórico-metodológicos sobre a avaliação nos MP?; Que orientações os MP trazem sobre a avaliação da leitura?; As propostas de ensino possibilitam realizar a avaliação formativa da leitura?

\section{Pressupostos teórico-metodológicos sobre a leitura nos MP}

Com relação à leitura, observamos que os dois MP trazem reflexões para o seu ensino de estudiosos que se posicionam a partir da concepção sociocognitivista, como Solé (1998), e da perspectiva interativa/dialógica, como Rojo (2004). Isso é observável, por exemplo, quando se faz alusão às estratégias de leitura (no MP Vontade de Saber) e quando se listam capacidades de leitura, como a de compreensão e a de apreciação e réplica (no MP Singular e Plura). Ainda que em ambos haja uma mescla de diferentes acepções de leitura, o que não é necessariamente ruim, porque o trabalho com tal prática exige um conjunto de conhecimentos e posturas diferenciadas do professor, os comentários sobre leitura apoiam-se, principalmente, no MP1, no pressuposto interacionista e, no MP2, na visão cognitivista. Como exemplo disso, destacamos este trecho: 
[...] é necessário que desenvolva também suas capacidades de apreciação, que envolvem recuperar o contexto de produção do texto e relacioná-lo ao que está escrito; ter claras as finalidades e metas da atividade de leitura; perceber relações de intertextualidade e de interdiscursividade [...]. (FIGUEIREDO; BALTHASAR; GOULART, 2012, p.11)

No tocante às estratégias de leitura, no MP da coleção Singular e Plural, encontra-se uma subseção para explicar as diversas capacidades e procedimentos de leitura. Na seção destinada ao estudo do texto, também são encontradas perguntas que podem levar os alunos à checagem de hipóteses levantadas antes da leitura do texto. Ressalta-se que as atividades, propostas a partir da leitura de textos procuram ativar capacidades e mobilizar estratégias diversas, de acordo com o gênero lido e com os objetivos da leitura.

Também há, neste Manual, a sugestão de leitura complementar "A qualidade da leitura", de Garcez, que discute o conceito de leitura e novamente apresenta os procedimentos de leitura, incorporando habilidades como: estabelecer um objetivo claro; identificar e sublinhar as palavras-chave; tomar notas; estudar o vocabulário; destacar divisões no texto para agrupá-las posteriormente etc.

Vemos assim que a coleção discorre bastante sobre estratégias de leitura; no entanto, não dá exemplos nem instrui o professor como desenvolver de modo sistemático um trabalho com essas estratégias.

No MP da coleção Vontade de Saber, não há seção específica que trate das estratégias de leitura. No entanto, apresentam-se, na seção que explicita as orientações didáticas e metodológicas - mais especificamente na subseção sobre a leitura na sala de aula -, algumas informações que podem ajudar a realizar um trabalho baseado em procedimentos, que lembram os propostos por Condemarín e Medina (2005):

- chamar atenção para as informações do título do texto;

- introduzir pequena síntese do texto;

- falar da estrutura composicional do texto ou sobre o portador; 
- falar sobre o autor do texto e a época em que o texto foi escrito;

- relacionar o texto com outros conhecidos;

- relacionar o texto com obras de arte. (TAVARES; CONSELVAN, 2012, p.18)

Com base nas informações sobre o trabalho proposto, verificamos que as estratégias de leitura seriam mobilizadas, nas coleções, a partir de perguntas de compreensão e interpretação do texto, as quais, de acordo com Solé (1998), são atividades avaliativas. Como não há explicitação quanto à leitura enquanto objeto de ensino, existe a possibilidade de não haver de fato o ensino de estratégias em sala de aula. Assim, não podemos esperar que

[...] os alunos aprendam o que não Ihes foi ensinado, nem vamos esperar que aprendam de uma só vez e para sempre. Trata-se apenas de fazer com a leitura o que se faz com outros métodos do ensino: mostrar como um especialista os maneja, planejar situações em que o aprendiz possa abordar progressivamente este manejo e ajudá-lo para que, partindo de onde se encontra, possa ir sempre um pouco além, no sentido do domínio autônomo. [...]

Aprender a ler requer que se ensine a ler. $O$ modelo de leitor oferecido pelo professor $e$ as atividades propostas para $o$ ensino e a aprendizagem da leitura não são um luxo, mas uma necessidade. (SOLÉ, 1998, p. 172-173)

Entendemos, então, que as estratégias de leitura devem ser tratadas no LD de maneira sistemática e passíveis de serem ensinadas, considerando-se as especificidades de cada gênero.

A fim de mostrar como as questões comentadas aparecem nos Manuais, no quadro abaixo, apresentamos as principais informações sobre o trabalho com leitura.

Quadro 1- Pressupostos teórico-metodológicos sobre leitura

\begin{tabular}{|c|c|}
\hline SINGULAR E PLURAL & VONTADE DE SABER \\
\hline $\begin{array}{l}\text { - A leitura é apresentada sob a perspectiva } \\
\text { dos múltiplos letramentos e de acordo } \\
\text { com os PCN; } \\
\text { - As atividades exploram textos } \\
\text { apresentados em diferentes suportes ou }\end{array}$ & $\begin{array}{l}\text { - A leitura é apresentada como interação } \\
\text { entre leitor e autor; } \\
\text { - A leitura envolve a ativação de } \\
\text { conhecimentos prévios; } \\
\text { - As atividades de leitura precisam } \\
\text { explorar as características do gênero, o }\end{array}$ \\
\hline
\end{tabular}


apresentados em diferentes esferas de circulação;

- Os gêneros são considerados como objetos de ensino-aprendizagem;

- A leitura é vista como uma situação de interlocução;

- As capacidades de decodificação, de compreensão e de apreciação e réplica precisam ser desenvolvidas;

- As atividades de leitura procuram ativar capacidades ou solicitar procedimentos diversos, de acordo com o gênero lido e os objetivos da leitura;

- O desenvolvimento das práticas de leitura requer um trabalho pontual com textos literários;

- O trabalho com leitura precisa focar questões de intertextualidade.

- As estratégias são assumidas como procedimentos estratégicos de leitura que podem ser adotados para tornar o processo de leitura mais produtivo.

Fonte: Elaborado pelas autoras autor do texto e a época em que o texto foi escrito, e relacionar o texto com outros conhecidos;

- A compreensão textual é mais uma atividade de relação de vários elementos do que a extração de uma informação objetiva de determinado enunciado;

- $\quad$ Os textos propostos devem apresentar diferentes linguagens, ser representativos de diferentes gêneros textuais que circulam na sociedade e abranger diversas esferas de circulação;

- $\quad$ As atividades de leitura devem levar o aluno a perceber situações de intertextualidade;

- $\quad$ Na leitura devem ser levados em conta os conhecimentos prévios dos alunos, estimulando-os a expor o que sabem sobre o tema.

Em síntese, podemos dizer que ambas as coleções são orientadas por concepções cognitivas e interacionistas de leitura e concordam que "a leitura é parte da interação verbal escrita, enquanto implica a participação cooperativa do leitor na interpretação e na reconstrução do sentido e das intenções pretendidas pelo autor" (ANTUNES, 2003, p. 66) e que envolve estratégias para sua realização.

\section{Pressupostos teórico-metodológicos sobre a avaliação nos MP}

Para especificar a visão sobre avaliação apresentada em cada coleção, destacamos no quadro abaixo uma síntese.

\section{Quadro 2- Pressupostos teórico-metodológicos sobre a avaliação}

\begin{tabular}{|l|l|}
\hline SINGULAR E PLURAL & VONTADE DE SABER \\
\hline - A avaliação deve ser um processo, com & - A avaliação deve ser vista como um \\
etapas interdependentes, e deve & conjunto de ações, estabelecidas com a \\
equalizar as responsabilidades no & intenção de alcançar informações sobre \\
contrato didático, para garantir aos & o que o aluno aprendeu, a forma como \\
alunos momentos e modos de regular as & aprendeu e em quais condições. \\
\hline
\end{tabular}


próprias aprendizagens, a partir da mediação do professor.

- No processo de avaliação, é importante articular algumas etapas como: informação aos alunos sobre as expectativas de aprendizagem, 0 percurso que se espera deles; levantamento de conhecimentos prévios relevantes; negociação de critérios para averiguação das aprendizagens em processo, permitindo a autoavaliação contínua; e a comparação do que foi aprendido com as expectativas iniciais, para a definição de retomadas ou progressos.

- O professor deve mediar a aprendizagem dos objetos de ensino, por meio de diálogos: anotações e devolutivas escritas. Esses modos avaliativos servirão para favorecer a autoavaliação, desenvolvendo a autonomia nas aprendizagens.

Fonte: Elaborado pelas autoras
- A avaliação deve ocorrer durante todo o processo de ensino-aprendizagem, e não em momentos específicos.

- A avaliação deve ser entendida basicamente de duas formas: como instrumento que permite ao professor analisar sua prática pedagógica e como instrumento que possibilite ao aluno verificar seus avanços, contribuindo para seu desenvolvimento.

- Quando se avalia as aprendizagens dos alunos, também se avalia o ensino ministrado;

- As avaliações devem explorar diferentes habilidades e considerar os diversos ritmos de aprendizagem dos alunos.

Como é possível perceber, por meio da síntese, os dois Manuais assumem a concepção formativa de avaliação, uma vez que destacam que ela deve ocorrer durante todo o processo de ensino-aprendizagem e ser feita com a finalidade de obter informações sobre o que o aluno aprendeu, de que forma e em quais condições. Esse posicionamento dos dois Manuais alinha-se ao que dizem os PCN, por exemplo:

\begin{abstract}
A avaliação deve possibilitar ao aluno a reflexão tanto sobre os conhecimentos construídos - o que sabe -, quanto sobre os processos pelos quais isso ocorreu - como conseguiu aprender. Ao identificar 0 que sabe, o aluno tem a possibilidade de delimitar o que precisa, ainda, aprender. Ao reconhecer como conseguiu aprender, o aluno tem a possibilidade de descobrir que podem existir outros modos de aprender, conhecer e de fazer. A apropriação de novos conceitos e procedimentos permite que 0 aluno possa realizar as atividades propostas com maior eficiência e autonomia. (BRASIL, 2006, p. 93)
\end{abstract}

Ambas as coleções também se aproximam do que Allal (1986, p. 177) menciona, isto é, que a avaliação deve "fornecer informações que permitam adaptar o ensino às diferenças individuais observadas na aprendizagem". 
Verificamos também que os dois MP procuram se adequar aos critérios de avaliação estabelecidos nas instruções do edital de convocação do PNLD/2014, 0 qual não determina nenhum critério eliminatório específico relativo ao trabalho com a avaliação e não traz nenhuma orientação precisa de que o livro do aluno deva favorecer um trabalho com leitura sob a perspectiva formativa. Nele, é apenas enfatizado que o MP deve "apresentar subsídios para a avaliação dos resultados de ensino, assim como para a ampliação e adaptação das propostas que figuram no(s) livro(s) do aluno" (BRASIL, 2013b, p. 71). Esse cumprimento do critério é executado parcialmente, na medida em que os Manuais apresentam mais informações teóricas do que práticas, o que é estranho se considerarmos que o MP tem por finalidade auxiliar o trabalho docente em sala de aula. Logo, deveria existir um equilíbrio entre teoria e procedimentos metodológicos.

\section{Orientações que os MP trazem sobre a avaliação da leitura}

A partir da descrição e análise dos dados, percebemos que os Manuais não abordam a avaliação da compreensão leitora. Talvez, isso aconteça porque o edital de convocação do PNLD/2014 (2013) não apresenta um critério quanto à importância da avaliação da leitura. E, considerando seu caráter prescritivo, haveria mais possibilidade de os Manuais apresentarem procedimentos, instrumentos e critérios avaliativos para a leitura se isso fosse solicitado às editoras, já que, conforme destacam Rojo e Batista (2003), o PNLD legisla a produção do LD.

Verificamos também que nem os pressupostos teórico-metodológicos nem as orientações específicas destinadas a cada capítulo do livro do aluno ajudam o professor (se este lê o MP, é claro) a ensinar e, sobretudo, a avaliar a leitura. As orientações contribuem muito pouco para o docente favorecer a formação de um aluno que saiba

ler, de maneira autônoma, textos de gêneros e temas com os quais tenha construído familiaridade: selecionando procedimentos de leitura adequados a diferentes objetivos e interesses, e a características do gênero e suporte; desenvolvendo sua capacidade de construir um 
conjunto de expectativas (pressuposições antecipadoras dos sentidos, da forma e da função do texto), apoiando-se em seus conhecimentos prévios sobre gênero, suporte e universo temático, bem como sobre saliências textuais recursos gráficos, imagens, dados da própria obra (índice, prefácio etc.); confirmando antecipações e inferências realizadas antes e durante a leitura; articulando o maior número possível de índices textuais e contextuais na construção do sentido do texto. (BRASIL, 1998, p.50)

No quadro abaixo, evidenciamos o que consideramos ser negligência dos Manuais quanto às orientações sobre a avaliação da leitura. 
Quadro 3- Negligências dos Manuais quanto à avaliação da leitura

\begin{tabular}{|l|ll|}
\hline \multicolumn{2}{|c|}{ SINGULAR E PLURAL } & \multicolumn{2}{|c|}{ VONTADE DE SABER } \\
\hline - Não há espaço que aborde & - Não aborda de forma particular o \\
especificamente a avaliação da leitura. & $\begin{array}{l}\text { tratamento que deve ser dado à } \\
\text { avaliação da leitura. }\end{array}$ \\
- $\begin{array}{l}\text { Na seção sobre orientações para a } \\
\text { avaliação, diz-se que alguns conteúdos da } \\
\text { disciplina de Língua Portuguesa não } \\
\text { demandam ser subordinados à } \\
\text { necessidade de avaliação, por exemplo, a } \\
\text { avaliação da aprendizagem da leitura. }\end{array}$ & \\
\hline
\end{tabular}

Fonte: Elaborado pelas autoras

Com base nisso, podemos dizer que os Manuais analisados não se constituem totalmente como um instrumento capaz de subsidiar adequadamente o uso da coleção pelo professor, porque faltam orientações precisas sobre o que é ensinar e avaliar leitura e como usar as atividades do livro do aluno para conduzir esse ensino.

\section{Relação entre as orientações sobre o ensino e a avaliação formativa da leitura}

Nos MP, observamos que as discussões teóricas e orientações metodológicas realizadas poderiam ser adotados durante o ensino de leitura e auxiliar a sua avaliação. Entretanto, falta estabelecer relação entre ensino e avaliação formativa da leitura. Por exemplo, no MP1, as autoras fazem comentários sobre a necessidade de definição de objetivos de leitura, uma das estratégias cognitivas citada por Solé (1998). Segundo elas, "ler um texto sem um objetivo é como se lançar sem uma bússola; fica muito mais difícil encontrar o caminho que nos levará a compreensão do que está escrito" (FIGUEIREDO; BALTHASAR; GOULART, 2012, p.11). Fica evidente assim que a definição do objetivo auxilia a escolha de estratégias adequadas, mas como fazer isso e como avaliar se os alunos estão se valendo da estratégia? Ainda de acordo com elas, há diversos procedimentos que podem ser usados para garantir de certa forma a compreensão de um texto. Mas, como se ensinam procedimentos de leitura? São questões que ficam em aberto nos MP e cujas respostas seriam decisivas 
para realizar um trabalho que viabilizasse o desenvolvimento das habilidades de leitura dos alunos.

Não há dúvidas de que teoricamente os MP são bem fundamentados. Contudo, questões relacionadas à didática, à forma como o professor vai apresentar os objetos de ensino e avaliar e regular a aprendizagem dos alunos não são tratadas, mesmo em seções destinadas a sugestões de atividades. Por exemplo, na seção $A$ avaliação no ensino de Língua Portuguesa, as autoras do MP2 dizem em que consiste a avaliação, entretanto não chegam a exemplificar de que forma isso pode ser feito na leitura e em outras práticas, conforme verificado no trecho abaixo.

Ainda nessa concepção, a avaliação deve ser entendida basicamente de duas maneiras: como instrumento que permite ao professor analisar sua prática pedagógica e como instrumento que possibilite ao aluno verificar seus avanços, contribuindo para seu crescimento intelectual e desenvolvimento de seu espírito crítico. (TAVARES; CONSELVAN, 2012, p. 27)

Alguns podem argumentar, dizendo que os livros didáticos trazem perguntas de interpretação de texto, que, para serem respondidas, exigem a mobilização de estratégias de leitura, como explicitado no MP1:

[...] independentemente da finalidade da leitura, as atividades relacionadas aos textos acabam por ativar as diversas capacidades e procedimentos de leitura e/ou levam os alunos a construíram sentidos tendo em vista os aspectos formais e discursivos relacionados ao texto. (FIGUEIREDO; BALTHASAR; GOULART, 2012, p.12)

Cabe, contudo, perguntar para que servem de fato as atividades de leitura (perguntas de compreensão e interpretação de texto)? Para ensinar leitura? Ou para avaliar leitura? Como destaca Solé (1998), a função das perguntas de interpretação não é ensinar e sim avaliar. Ela sugere como solução o ensino de estratégias, o que não é especificado nos Manuais, embora haja a alusão a várias delas, como: definição de objetivos; levantamento de hipóteses; ativação de conhecimento prévio; elaboração de inferências; apreciação de texto etc. 
Podemos dizer assim que o ensino de leitura é algo ainda nebuloso nos MP analisados, o que prejudica, por conseguinte, que o professor realize a avaliação da leitura e prepare atividades para ajudar os alunos a superar suas dificuldades, porque, ainda que neles sejam expostos os pressupostos da avaliação formativa, não se discute a avaliação da leitura, a qual pressupõe conhecer o que de fato está sendo ensinado, nem se explicita como ensinar procedimentos variados de leitura conforme o gênero. Seriam esses aprendidos indiretamente pelo ato de ler? Eles seriam ensináveis? Como se aprende a ler?

Considerando as discussões de Solé (1998) e Koch e Elias (2014), pelo modo como as orientações são apresentadas nos MP e pela natureza do trabalho proposto com leitura no livro do aluno, é possível dizer que o professor não realizará ações que viabilizem a aprendizagem da leitura; conseguirá no máximo avaliar, por meio de fichas, se o aluno já domina ou não certas habilidades. 0 docente de posse do livro, se depender exclusivamente das informações presentes nos MP, não conseguirá certamente desenvolver um trabalho direto e sistemático com leitura, pois as seções destinadas a essa prática no livro do aluno possibilitam apenas a leitura de textos, seguida de resolução de exercícios de interpretação, que vão servir para verificar o que o aluno é capaz de fazer. A natureza avaliativa das atividades de leitura é inclusive destacada no próprio MP1:

Em caráter de avaliação inicial são oferecidas, nas seções Converse com a turma (Caderno de Leitura e produção), Conversa afinada (Caderno de Práticas de literatura) e Como é que é? (Caderno de Estudos de língua e linguagem), perguntas para serem discutidas coletivamente, a fim de propiciar o levantamento e compartilhamento de conhecimentos prévios relevantes para as aprendizagens esperadas". (FIGUEIREDO; BALTHASAR; GOULART, 2012, p.23)

Quanto às informações presentes nos Manuais, essas levam, sobretudo, o professor a perceber que na atividade de ler estão envolvidas capacidades e estratégias e que se trata de um ato interativo, do qual participam autor, texto e 
leitor, bem como a reconhecer os objetivos da seção destinada ao trabalho com leitura:

O objetivo principal dessa seção é promover as habilidades de leitura por meio de práticas que beneficiem a conexão com o que o aluno já sabe e expandem sua capacidade de interpretação e de conhecimento de mundo. (TAVARES; CONSELVAN, 2012, p. 4)

Além disso, o educador terá acesso a sugestões de respostas e de como realizar a mediação entre o conhecimento e o aluno, as quais consideramos genéricas e sem foco no ensino e avaliação da leitura, como podemos observar nestes trechos:

$\mathrm{Na}$ mediação da leitura ajude os alunos a compreenderem e interpretarem a sequência narrativa que se coloca tanto pelos balões de fala, como pelos desenhos [...]

Na mediação das questões de 1 a 4, procure incentivar os alunos a se colocarem com argumentos e promova a troca de opiniões entre eles. (FIGUEIREDO; BALTHASAR; GOULART, 2012, p.68 e 69).

Explicar aos alunos que a relação entre pais e filhos sofreu mudanças ao longo dos tempos. Se antes a educação era mais rígida e repleta de limites e regras impostas, hoje em dia, há a tentativa de estabelecer um maior diálogo. No entanto, essa abertura acabou trazendo problemas que precisam ser discutidos para que se consiga um convívio melhor e mais eficaz dentro da família. (TAVARES; CONSELVAN, 2012, p. 36)

Com base na análise dos MP do $8^{\circ}$ ano das coleções Singular e Plural e Vontade de Saber, podemos dizer que, embora já haja uma discussão sobre leitura na perspectiva de língua como interação e sobre avaliação na abordagem formativa, não há orientações precisas sobre como ensinar e avaliar a leitura. Faz-se uma abordagem bastante significativa sobre os diferentes objetivos, as capacidades e as estratégias de leitura; porém, seria isso o suficiente para orientar o professor a realizar um trabalho cujo foco seja a leitura? Seria isso o suficiente para levar o professor a adotar uma prática de avaliação formativa da leitura? 


\section{Considerações finais}

Buscando verificar como as orientações presentes no LD possibilitam ao professor realizar um trabalho que integre ensino, avaliação e aprendizagem, nesta pesquisa, identificamos e explicamos os fatores que interferem na configuração que o Manual tem atualmente, a fim de mostrar que o MP é um material que é regulado pelo Governo.

Ao finalizar esta pesquisa, verificamos que os Manuais defendem que 0 ensino da leitura seja feito por meio de diferentes tipos de gêneros e linguagens e abranja questões de intertextualidade, sendo esse posicionamento condizente com as orientações presentes nos PCN e com as exigências previstas no edital de convocação do PNLD/2014. Constatamos também que os dois MP trazem reflexões para o ensino de leitura, tomando como base estudiosos de diferentes linhas, cognitivista e interativa/dialógica. Além disso, evidenciamos que não há, nos Manuais, orientações que considerem as estratégias de compreensão leitora como um tipo específico de procedimento que pode ser ensinado aos alunos; elas aparecem apenas como meios para o professor realizar o trabalho.

Em relação às orientações para a avaliação, percebemos que os Manuais assumem a concepção formativa de avaliação, pois destacam que ela deve ocorrer durante todo o processo de ensino-aprendizagem e ter como fim a obtenção de informações sobre o que o aluno aprendeu, de que forma e em quais condições.

De um modo geral, concluímos que os pressupostos teórico-metodológicos e as orientações específicas destinadas às atividades do livro do aluno pouco ajudam o professor a ensinar e, sobretudo, a avaliar a leitura e que a avaliação não aparece como algo articulado ao ensino e à aprendizagem nos MP analisados.

\section{Referências}

ALLAL, Linda. Estratégias de avaliação formativa: concepções psicopedagógicas e modalidades de aplicação. In: ALLAL, Linda; CARDINET, Jean; PERRENOUD, Philippe. Avaliação formativa num ensino diferenciado. Tradução de Clara Moura Lourenço; José Afonso Baptista. Coimbra: Almedina, 1986. p. 175-205. 
ANTUNES, Irandé. Aula de português. encontro e interação. São Paulo: Parábola. 2003.

BAKHTIN, Mikhail (Volochinov). O discurso no romance. In: estética e de literatura. 3. ed. São Paulo: Ed. da UNESP, 1993. Questões de

BATISTA, Antônio Augusto Gomes. O conceito de "livros didáticos". In: BATISTA, Antônio Augusto Gomes; GALVÃO, Ana Maria de Oliveira. Livros escolares de leitura no Brasil: elementos para uma história. Campinas, SP: Mercado de Letras, 2009. p. 41-73.

BESERRA, N. S. Avaliação da compreensão leitora: em busca da relevância. In: MARCUSCHI, B.; SUASSUNA, L. (Org.). Avaliação em língua portuguesa: contribuições para a prática pedagógica. Belo Horizonte: Ed. Autêntica, 2007. p. 45-60.

BRASIL. Secretaria de Educação Fundamental. Parâmetros curriculares nacionais: $5^{a}$ a $8^{a}$ séries. Brasília, 1998. Disponível em: <http://portal.mec.gov.br/seb/arquivos/ pdf/portugues.pdf>. Acesso em: 5 nov. 2016.

BRASIL. Secretaria de Educação Fundamental. Parâmetros curriculares nacionais : introdução aos parâmetros curriculares nacionais. Brasília, 2006.

BRASIL. Fundo Nacional de Desenvolvimento da Educação. Apresentação, 2012. Disponível em: <http://www.fnde.gov.br/programas/livro-didatico/livro-didaticoapresentacao>. Acesso em: 25 fev. 2016.

BRASIL. Fundo Nacional de Desenvolvimento da Educação. Guia PNLD 2014. Brasília: MEC/SEF, 2013a. Disponível em: <http://www.fnde.gov.br/programas/livrodidatico/guias-do-pnld/item/4661-guia-pnld-2014>. Acesso em: 5 nov. 2016.

BRASIL, Fundo Nacional de Desenvolvimento da Educação. Edital PNLD 2014. Brasília: MEC/SEF, 2013b. Disponível em: <http://www.fnde.gov.br/programas/livrodidatico/livro-didatico-editais/item/3963-pnld-2014-anos-finais-do-ensinofundamental>. Acesso em: 5 nov. 2016.

BRITTO, Luiz Percival Leme. Livro didático e autonomia docente. SCRIPTA, Belo Horizonte, v. 6, n. 11, p. 162-170, 2002.

BUNZEN, Clécio; ROJO, Roxane Helena Rodrigues. Livro didático de língua portuguesa como gênero do discurso: autoria e estilo. In: VAL, M. da G. C.; MARCUSCHI, B. (Org.). Livros didáticos de língua portuguesa: letramento e cidadania. Belo Horizonte: Ceale/Autêntica, 2005. p. 73-117.

COLOMER, Teresa; CAMPS, Anna. Ensinar a ler, ensinar a compreender. Porto Alegre, 2002.

CONDEMARÍN, Mabel; MEDINA, Alejandra. Avaliação autêntica: um meio para melhorar as competências em linguagem e comunicação. Tradução de Fátima Murad. Porto Alegre: Artmed, 2005.

DIONISIO, Ângela Paiva; BEZERRA, Maria Auxiliadora. O livro didático de português. múltiplos olhares. Rio de Janeiro: Editora Lucerna, 2001. 
FERNANDES, Domingos. Articulação da aprendizagem, da avaliação e do ensino: Questões teóricas, práticas e metodológicas. In: ALVES, Maria Palmira; KETELE, JeanMarie de (Org.). Do currículo à avaliação, da avaliação ao currículo. Porto Alegre: Porto Editora, 2011. p. 131-142.

FIGUEIREDO, Laura de; BALTHASAR, Marisa; GOULART, Shirley. Singular e plural: leitura, produção e Estudos de linguagem. São Paulo: Moderna, 2012.

GERHARDT, Tatiana Engel. SILVEIRA, Denise Tolfo. Métodos de pesquisa. Porto Alegre: Editora da UFRGS, 2009.

HADJI, Charles. Ajudar os alunos a fazer a autorregulação da sua aprendizagem: Por quê? Como? (Visando um ensino construtivista). Pinhais: Editora Melo, 2011.

HOFFMAN, Jussara Maria Lerch. Avaliação - mito e desafio: uma perspectiva construtivista. Porto Alegre: Mediação, 2009.

$\mathrm{KOCH}$, Ingedore Villaça; ELIAS, Vanda Maria. Ler e compreender os sentidos do texto. São Paulo: Contexto, 2014.

MARCUSCHI, Luiz Antônio. Produção textual, análise de gêneros e compreensão. São Paulo: Parábola Editorial, 2008.

ROJO, Roxane Helena Rodrigues. Letramento e capacidades de leitura para a cidadania. São Paulo, 2004. Disponível em: <http://arquivos.info.ufrn.br/ arquivos/2013121153a8f1155045828c12733b68e/Letramento_e_capacidade_de_leitura _pra_cidadania_2004.pdf.>. Acesso em: 3 nov. 2016.

ROJO, Roxane Helena Rodrigues; BATISTA, Antônio Augusto Gomes. Livro didático de língua portuguesa, letramento e cultura da escrita. Campinas, SP: Mercado de Letras, 2003.

SOARES, Ricardo Pereira. Compras governamentais para o Programa Nacional do Livro Didático: uma discussão sobre a eficiência do governo. Brasília, DF: Instituto de Pesquisa Econômica Aplicada, 2007. (Textos para Discussão, no 1307).

SOARES, Magda. Novas práticas de leitura e escrita: letramento na cibercultura. Revista Educação e Sociedade, Campinas, v. 23, n. 81, p. 143-160, dez. 2002.

SOARES, Magda. O livro didático como fonte para a história da leitura e da formação do professor-leitor. In: MARINHO, M. (Org.). Ler e navegar: espaços e percursos da leitura. Campinas: Mercado de Letras/ALB, 2001. p. 31-76.

SOLÉ, Isabel. Estratégias de leitura. 6. ed. Porto Alegre: Penso, 1998.

SUASSUNA, Lívia. Paradigmas de avaliação: uma visão panorâmica. In: MARCUSCHI, B.; SUASSUNA, L. (Org.). Avaliação em língua portuguesa: contribuições para a prática pedagógica. Belo Horizonte: Autêntica, 2007.

TARDIF, Maurice. Saberes docentes e formação profissional. Petrópolis: Editora Vozes, 2008. 
TAVARES, Rosemeire Aparecida Alves; CONSELVAN, Tatiane Brugnerotto. Vontade de saber português, $8^{\circ}$ ano. São Paulo: FTD, 2012. 